\title{
O Estado e as Comunicações no Brasil
}

\section{State and Communications in Brazil}

\author{
Octavio Penna Pieranti ${ }^{1}$
}

\section{Resumo}

De forma pioneira na história do Brasil, os parlamentares que compuseram a Assembléia Nacional Constituinte reservaram um capítulo à Comunicação Social na Constituição Federal promulgada em 1988. De acordo com o documento, a liberdade de imprensa foi plenamente assegurada, a posse das emissoras de radiodifusão foi teoricamente limitada e a programação delas, rediscutida. Este artigo analisa a relação entre Estado e imprensa no Brasil contemporâneo, com base no Capítulo V do Título VIII da Constituição Federal, relativo à Comunicação Social. Por fim, é questionada a eficiência da Constituição Federal no tocante às Comunicações, visto que vários princípios do documento, promulgado há mais de 15 anos, ainda não foram postos em prática.

Palavras-chave: Estado, Comunicações, Constituição Federal, Imprensa

\begin{abstract}
For the first time in Brazilian history, the parliamentarians who had composed the Constitutional National Assembly had reserved a chapter to the Social Communication in the Federal Constitution, promulgated in 1988. According to the document, the press freedom was fully assured, the ownership of the broadcasting stations was theoretically limited and the programs of them, discussed. This article analyzes the relation between State and the press in Brazil, based on Federal Constitution's Chapter V of Heading VIII, relative to the Social Communication. Finally, the efficiency of the Federal Constitution, relatively to the Communications, is questioned, because some principles of the document, promulgated more than 15 years ago, are still ignored.
\end{abstract}

Keywords: State, Communications, Federal Constitution, Press

\section{Introdução}

A Constituição Federal promulgada em 1988, ao contrário de suas antecessoras, destinou capítulo pioneiro ao campo da comunicação social. Mais que um marco (pelo menos, em tese) capaz de estimular uma nova regulamentação para o setor, o capítulo V do título VIII da Carta Magna analisou a imprensa e a radiodifusão como elementos importantes para a democracia, em relação aos quais deveria vigorar uma legislação moderna, amparada em princípios condizentes com o fim do regime autoritário das décadas imediatamente anteriores.

Este artigo tem como objetivo analisar a relação entre o Estado e os meios de comunicação no Brasil contemporâneo, tomando por base o mencionado capítulo V do título VIII da Constituição Federal. Pretende, ainda, questionar indiretamente a eficiência do texto constitucional como ponto de partida para a elaboração de políticas públicas para o setor de comunicação social, ora carente de projetos.

Os parlamentares que compuseram a Assembléia Nacional Constituinte na década de 1980 aprovaram cinco artigos na Carta Magna unicamente ligados ao campo em estudo, além de incisos referentes à imprensa e à radiodifusão em outros capítulos do mesmo documento. $\mathrm{O}$ artigo 220 trata da liberdade de expressão. $\mathrm{O}$ artigo 221

\footnotetext{
${ }^{1}$ Doutorando em Administração Pública pela Escola Brasileira de Administração Pública e de Empresa da Fundação Getulio Vargas - EBAPE/FGV. Endereço: Praia de Botafogo,190 - sala 515 Botafogo - Rio de Janeiro/RJ - Brasil - CEP: 22250-900 - Email: octavio@fgvmail.br

Artigo recebido em novembro de 2005 e aceito para publicação em maio de 2006.
} 
estabelece as características que devem nortear a programação das emissoras de rádio e de televisão. $\mathrm{O}$ artigo 222 versa sobre a propriedade das empresas de radiodifusão e de imprensa. O artigo 223 muda a regulamentação da outorga e da renovação de concessões de emissoras de radiodifusão. $\mathrm{O}$ artigo 224 determina a criação de órgão fiscalizador da comunicação social.

No tocante à estrutura do artigo, são analisadas, em seções separadas, dois princípios ligados à essência da democracia, defendidos implicitamente na Carta Magna de 1988 e explicitados por Robert Dahl - a existência de liberdade de expressão e de fontes de informação diversificadas. Antes dessa análise, porém, é necessário discutir os princípios democráticos e o modo como os meios de comunicação estão envolvidos com tais princípios

\section{Democracia e meios de comunicação}

Historicamente, em contextos democráticos, Estado e meios de comunicação desenvolvem uma relação contraditória. Ao Estado, cabe não apenas regular os meios de comunicação, mas também garantir a liberdade de imprensa, em qualquer mídia (impressa, televisiva, radiofônica ou qualquer outra), normalmente limitada por legislação punitiva aplicada posteriormente à divulgação de informações. A punição, assim, ocorre em casos em que excessos tenham sido cometidos, sendo prevista, no mais das vezes, por manancial legal específico, como uma lei de imprensa.

A interpretação dos meios de comunicação como fundamentais para o funcionamento de Estados modernos está presente na discussão de Robert Dahl sobre a poliarquia. Segundo o autor (1991), trata-se de um conceito flexível, que pode ser interpretado de diversas formas:

- como resultado de tentativas de democratização das instituições do Estado;

- como um sistema político específico;

- como forma de controle político visando resultados eleitorais;

- como um sistema de garantia de direitos políticos; ou

- como um conjunto de instituições necessárias ao funcionamento do processo democrático em larga escala (interpretação que particularmente interessa a este artigo).

De acordo com Dahl (2001), são seis as instituições essenciais à poliarquia. Quatro não estão diretamente relacionadas com as atividades ligadas à comunicação (funcionários eleitos; eleições livres, justas e freqüentes; autonomia para as associações e cidadania inclusiva). Outras duas estão intimamente ligadas a esse setor: liberdade de expressão e fontes de informação diversificadas.

Na visão do autor, a liberdade de expressão e o acesso a fontes de informação diversificadas estão relacionados com a satisfação de critérios básicos para a vigência de um regime democrático. Expressar-se livremente é prérequisito para que os cidadãos possam se posicionar em relação a cenários diversos, participando da vida política. Essa participação requer uma compreensão esclarecida sobre os fatores que cercam a sociedade, o que leva a uma possibilidade, anda segundo o autor, de interferência na agenda programática do governo. $\mathrm{O}$ acesso a fontes diferenciadas de informação está igualmente ligado à idéia de possibilidade de um maior esclarecimento da população, levando à participação consciente no cenário político.

Para atingir esse fim, a imprensa tem, como uma de suas funções assinaladas por Herman e Chomsky (2003), a fiscalização dos grandes grupos políticos e econômicos, que, por sua vez, dela necessitam. Os meios de comunicação, cujo conteúdo é, em parte, noticioso, tornam-se especialmente atrativos em época de eleições e de cenários de crises político-econômicas, sendo palco para o desempenho dos atores públicos em busca de ganhos pessoais. Nesse ponto, estabelece-se um impasse previsível. A julgar pela compreensão contemporânea sobre o que seja democracia, a imprensa deve ser livre (numa extensão do princípio da liberdade de expressão) e a sociedade deve ter acesso a fontes múltiplas de informação, que têm, como uma de suas funções, a fiscalização do Estado e dos atores a ele ligados. Os meios de comunicação são, outrossim, importantes para esses mesmos ato- 
res, graças à sua prerrogativa de difusão da informação. A acomodação desse impasse envolve uma constante busca de ampliação, por parte dos atores ligados ao Estado, de sua influência nos meios de comunicação, logo, não mais independentes por completo e, na prática, atrelados a eventuais ou constantes interesses pessoais.

Althusser (1987) chegou a relacionar os meios de comunicação como um dos aparelhos ideológicos de Estado, ou seja, instituições que, mesmo oficialmente controladas pela iniciativa privada, reproduzem a ideologia do Estado e as relações de produção vigentes. Avançando por caminho semelhante, Vieira (1984, p.22) lembra que

Os meios de comunicação de massa são aparelhos ideológicos do Estado, mas não são apenas isso, porque, no que refletem o Estado, eles também fazem o Estado, reproduzem a ideologia do mercado e o mercado mesmo, o produto e o consumo do produto, mas, acima de tudo, a existência de um sistema fundado no consumo, ou no mercado, e, afinal, o que os aparelhos reproduzem mesmo é o mecanismo das relações de produção.

Não se trata de afirmar neste artigo que o Estado brasileiro contemporâneo inapelavelmente controla os meios de comunicação, o que seria falacioso. Trata-se, sim, nesta análise, de compreender a relação entre meios de comunicação e Estado como contraditória, marcada por situações de conflito que opõem interesses pessoais a princípios democráticos.

\section{Liberdade de expressão}

Nunca, na história da República no Brasil, a liberdade de expressão e o veto à censura ficaram tão explícitos quanto na Constituição Federal de 1988. A Carta de 1967, modificada em 1969, previa a censura a espetáculos e diversões públicas, bem como a condenação de propagandas de "subversão da ordem" e contra "a moral e os bons costumes" em jornais, livros e periódicos (CAMPANHOLE, 1989, p.252). Deve ser observado que é passível de múltiplas interpretações o conceito de subversão da ordem, moral e bons costumes, e que a censura de tais matérias é, portanto, possível, dependendo do discernimento do censor e do grau de autoritarismo do governo. A censura à imprensa também era prevista no texto constitucional, no artigo 156, em caso de declaração de estado de sítio (SODRÉ, 1999). Já a Constituição Federal de 1946 fazia uso de expressão parecida, em seu artigo $141, \S 5^{\circ}$, no que tange à publicação de livros e periódicos, vedando a propaganda de "processos violentos para subverter a ordem política e social." (CAMPANHOLE, 1989, p.446). A censura também era aplicável a espetáculos e diversões públicas.

Coube à Constituição Federal de 1988 defender a liberdade de expressão, de forma clara, em seu artigo $5^{\circ}$ (cláusula pétrea). O artigo 220 fala ainda na proibição de restrições "à manifestação do pensamento, à criação, à expressão e à informação", explicitando no $\$ 2^{\circ}$ que "é vedada toda e qualquer censura de natureza política, ideológica e artística." (CAMPANHOLE, 1989, p.107). O mesmo artigo, em seu §3ํㅡㄹ lembra que caberá a lei federal regular os espetáculos públicos e que é tarefa do Poder Público prestar informações sobre a sua natureza.

Esses princípios constitucionais são diferentes dos da Lei de Imprensa de 1967, ainda vigente. Pela inexistência de legislação mais recente, a Lei de Imprensa tem sido interpretada de forma parcial, sem que haja desrespeito à Constituição Federal.

Ao abordar discussão relativa à liberdade de imprensa, Arbex Júnior (2001) aponta a confusão entre esse conceito e o de liberdade de empresa. O primeiro refere-se a uma liberdade pública, fruto de conquistas em ambiente democrático, que não pode ser privatizada, ou seja, interpretada como bem de empresas específicas. Entretanto, o autor observa que, geralmente, a liberdade de imprensa é discutida como se fosse o direito que os empresários do setor têm de publicar o que julgam ser de interesse público. Essa, porém, é a liberdade de empresa, vinculada às idiossincrasias de pessoas específicas.

É preciso considerar que existe não apenas a censura externa, praticada pelo Poder Público, como também a interna, praticada por ocupantes de cargos de chefia de publicações ou de programas de cunho jornalístico. En- 
quanto a primeira é vedada pela Constituição Federal, a segunda não é regulamentada, fazendo parte da rotina de empresas jornalísticas privadas. Normalmente, essa prática é defendida como zelo aos interesses dos órgãos jornalísticos - interesses não fundamentalmente ligados à práxis jornalística nem ao atendimento de demandas sociais, mas como forma de defesa de pessoas, grupos ou empresas importantes para o funcionamento do órgão. Nesses casos, o atendimento de interesses privados supera, do ponto de vista empresarial, o interesse da sociedade em obter informações.

Em alguns países - o que não é o caso do Brasil -, a tensão entre as liberdades de empresa e de imprensa é minorada graças à criação de mecanismos legais conhecidos como "cláusulas de consciência". Nas nações em que elas vigoram, é facultada ao jornalista a recusa de redigir e publicar textos que firam sua honra ou contenham distorções dos acontecimentos, ficando o profissional protegido contra possíveis punições por parte de seu empregador.

Cabe, aqui, questionar a natureza das empresas jornalísticas no Brasil. De acordo com Arbex Júnior, são empresas como quaisquer outras, não encarando o seu papel em Estados democráticos como socialmente diferentes do de outros grupos da iniciativa privada. A mídia, porém, não pode permanecer infensa aos fatos, que, dependendo de sua força e de sua influência na sociedade, terminam por se impor como notícias.

O artigo 220, $\S 5^{\circ}$ impede a ocorrência de monopólio ou oligopólios nos meios de comunicação. Essa proibição será analisada mais adiante, quando for abordada a distribuição de concessões de emissoras de rádio e de televisão. Em um primeiro momento, deve ser ressaltado que é prática comum, no Brasil, a propriedade cruzada, ou seja, a posse de jornais, revistas, emissoras de rádio e de televisão num mesmo município por um mesmo grupo. Essa prática não é explicitamente proibida pelo texto constitucional, mas vai de encontro ao princípio de pluralidade de fontes de informação e de opinião. Esse problema chegou a ser discutido em projeto de lei do ministro das Comunicações do primeiro governo Fernando Henrique Cardoso, Sérgio Motta, porém, depois da sua morte, foi adiada a intenção de limitar a propriedade cruzada.

\section{Fontes de informação diversificadas}

A existência de fontes alternativas de informação depende de uma estrutura legal que impossibilite a concentração da posse dos meios de comunicação e permita o acesso de diferentes grupos aos mesmos. Essa condição é ainda mais nítida em relação às emissoras de radiodifusão: como é limitado o espectro de frequiências disponíveis, elas são entendidas como um bem público e, conseqüentemente, concedidas pelo Estado. Os critérios de outorga das concessões estão, assim, diretamente ligados à possibilidade de existência de fontes alternativas de informação.

Antes mesmo da promulgação da Constituição Federal de 1988 já existiam marcos legais, criados na década de 1960 e ainda em vigor, limitando a posse de emissoras de radiodifusão. Arcaicos, não prevêem figuras jurídicas hodiernas, como também não se ajustam mais às exigências tecnológicas da área. Mais que arcaicos, esses marcos legais são desrespeitados, incapazes de constituir um entrave à expansão de poderosos grupos econômicos e políticos. A associação através de redes e a posse de diversas emissoras por membros de um mesmo grupo econômico, por exemplo, são alternativas que possibilitam, em tese, a consolidação de conglomerados de informação, driblando as limitações legais à formação de oligopólios.

A Carta Magna de 1988 esboça esforço em oferecer subsídios para uma maior fiscalização no setor. Na redação original de seu artigo 222, manteve a posse de emissoras de radiodifusão reservada a brasileiros natos, estendendo-a também, a partir de sua promulgação, a brasileiros naturalizados. No artigo 223, a Constituição Federal incorpora o Poder Legislativo à rotina do setor, como o responsável pela fiscalização das outorgas e das renovações de concessões de emissoras, historicamente feitas pelo Poder Executivo, sem que houvesse necessariamente o envolvimento de qualquer outro ator político. 
O efeito dessa regulamentação é limitado. Em 2002, em face das crescentes dívidas das empresas de comunicação brasileiras, foram aprovadas uma emenda constitucional ao artigo 222 e a lei ${ }^{\circ} 10.610$ (BRASIL, 2002), abrindo as empresas de radiodifusão a investimentos estrangeiros, desde que limitados a 30\% do capital total. Contudo, a fiscalização do Poder Legislativo se revelou inócua. Como constata Roldão (1999), até o fim da década de 1990 não havia qualquer registro de negativa por parte dos parlamentares quanto à renovação das concessões.

Uma possível explicação para a falta de deliberação acerca de legislação sólida referente a essa temática no Congresso Nacional seria o notório interesse dos parlamentares por essas emissoras. Historicamente, desde o início da Nova República, cerca de $25 \%$ dos congressistas têm relações pessoais com empresas de radiodifusão, seja na gestão ou na composição acionária destas. Parte das concessões foi ganha graças a uma prática comum na história recente da democracia brasileira: o uso de emissoras como moeda de troca na relação com o Poder Executivo.

Motter (1994) relacionou a distribuição de concessões durante a vigência da Assembléia Nacional Constituinte com o processo de negociação envolvendo os poderes Executivo e Legislativo. O autor constatou que em 1985 foram distribuídas pelo presidente José Sarney 127 concessões; em 1986, 154; em 1987, 208 e, em 1988, durante os 10 meses que antecederam à promulgação da nova Constituição Federal, 539 (52\% do total do governo). Ao todo, foram outorgadas 1.028 concessões $-30,9 \%$ de todas as 3.300 feitas desde 1934 .

Dos premiados pelo governo Sarney, 91 eram parlamentares que receberam uma ou mais concessões em nome próprio, de parentes ou de amigos. Podemos concluir, então, que 16,3\% dos 559 parlamentares constituintes receberam concessões de emissoras de rádio e de televisão. Desses 91 parlamentares, 84 (92,3\%) votaram a favor do presidencialismo e $82(90,1 \%)$ a favor da prorrogação do mandato de José Sarney para cinco anos, dois projetos de evidente interesse do Poder Executivo. Além desses, outros 55 parlamentares já eram donos de rádios antes do governo Sarney e não receberam novas concessões, o que permite inferir que $26,1 \%$ dos parlamentares tinham interesses diretos, como proprietários de empresas de radiodifusão, na elaboração do capítulo V do título VIII da Constituição Federal.

A fiscalização das concessões pelo Congresso Nacional, determinada pela Constituição Federal de 1988, não evitou a utilização política da distribuição de concessões nos anos posteriores à promulgação da Carta. Segundo Costa e Brener (1997), o governo Fernando Henrique Cardoso valeu-se da distribuição de retransmissoras de televisão (RTV) para aprovar a emenda da reeleição.

As retransmissoras de televisão (RTV), reguladas pelo Decreto $n^{0}$ 81.600, de 1978, revogado em 1998, não eram objetos de concessão, já que deveriam ser simples repetidoras de sinal. A criação de RTVs dependia apenas de portaria do ministro das Comunicações, cargo ocupado na época por Sérgio Motta, considerado um dos principais e mais fiéis assessores de Fernando Henrique Cardoso. Havia uma peculiaridade na legislação sobre RTVs: poderiam ser inseridos em sua programação até $15 \%$ de programas próprios, quando elas funcionassem como repetidoras de sinal de emissoras educativas ou na região conhecida como Amazônia Legal, que abrange toda a região Norte, o Mato Grosso e parte do Maranhão. No primeiro governo de FHC foram distribuídas, até a votação da emenda da reeleição, 1.848 RTVs, 268 das quais entregues a entidades ou empresas controladas por 87 políticos, dentre os quais 19 deputados federais e seis senadores (todos favoráveis à emenda), governadores, prefeitos, deputados estaduais e ex-ocupantes de cargos públicos. A distribuição de concessões aumentou muito em 1996, principalmente em dezembro, mês em que foram liberadas 400 RTVs. Em 28 de janeiro de 1997, um mês depois do aumento de autorizações, a Câmara dos Deputados aprovou, em primeiro turno, a emenda da reeleição com 335 votos, 27 a mais que o número mínimo necessário.

O oferecimento de concessões não significou a formação de fontes alternativas de informação. A partir de 1995, o governo Fernando Henrique Cardoso estabeleceu nova regra para as concessões de emissoras de rádio e televisão (BRASIL, 1995), tornando-as, então, licitações públicas. Ainda que seja essa a tradicional forma de se buscar oficialmente transparência em negociações com verba pública, figuram, nesse modelo, outras limitações. Como frisa Roldão (1999), nesse setor, licitações, por si só, apenas criam a possibilidade de se trocar o 
critério político pelo econômico, não ampliando o acesso de outros setores da sociedade civil à radiodifusão comercial. Como é possível inferir, fica ainda mais difícil a participação de outros atores nesse mercado, pois os recursos que têm disponíveis são, não raro, inferiores aos arrecadados por empresas já consolidadas. Nesse sentido, o modelo de distribuição de concessões mediante licitações públicas pode vir a ser ainda mais concentrador. A formação de fontes alternativas de informação é ainda mais dificultada pelos altos investimentos necessários a empresas de comunicação - incluídas, aí, não só as emissoras de rádio e de televisão, mas também a mídia impressa.

A difícil fiscalização no setor pode ser exemplificada pelo episódio envolvendo o Conselho de Comunicação Social (CCS). Durante a vigência da Assembléia Nacional Constituinte, a deputada e jornalista Cristina Tavares defendeu a aprovação de um conselho com poderes normativos para regular as comunicações no país. $\mathrm{O}$ conselho outorgaria concessões, fiscalizaria as emissoras de radiodifusão e de imprensa e zelaria pelos princípios defendidos nos artigos referentes à Comunicação Social na Constituição Federal. Seria, pelo menos em tese, uma barreira capaz de dificultar arbitrariedades.

A proposta não foi aprovada pelos parlamentares constituintes. O Conselho de Comunicação Social (CCS) regulamentado pelo artigo 224 da Constituição Federal é um simples órgão auxiliar do Congresso Nacional, ficando sua elaboração a cargo de lei posterior. Em 30 de dezembro de 1991, mais de três anos depois da promulgação da Carta, o então presidente da República, Fernando Collor de Melo, sancionou a Lei n⿳o 8.389, que instituía o Conselho de Comunicação Social. Segundo o artigo $2^{\circ}$ da lei, esse conselho ficava responsável pela elaboração de pareceres, recomendações e estudos solicitados pelo Congresso Nacional, papel bem diferente, portanto, do imaginado durante a Assembléia Nacional Constituinte. Pelo artigo $8^{\circ}$ da mesma lei, o CCS seria instalado em até três meses.

No dia 25 de junho de 2002, ou seja, mais de 10 anos depois de publicada a Lei no 8.389 e mais de 13 anos após a promulgação da Constituição Federal, o Conselho de Comunicação Social reuniu-se pela primeira vez. Era formado, de acordo com a lei, por três membros de associações representativas das empresas de radiodifusão e de imprensa, um engenheiro com conhecimentos comprovados em comunicação social, quatro representantes de entidades classistas de profissionais do setor e cinco representantes da sociedade civil, todos ligados ao jornalismo e à radiodifusão. Por seus próprios membros o Conselho de Comunicação Social foi reconhecido, mais de uma vez, como um órgão com poder e influência reduzidos, incapaz de uma atuação efetiva no setor (BRASIL, 2004).

Em seus dois primeiros anos de existência, o conselho formou comissões para estudar a concentração da mídia brasileira, radiodifusão comunitária, qualidade da programação, tecnologia digital e TV a cabo, sem nunca exercer um papel deliberativo. Os estudos e pareceres não são, assim, garantias de mudanças na regulação do setor ou, sequer, ponto de partida para obrigatória reflexão dos parlamentares. O poder reduzido do Conselho de Comunicação Social, reconhecido pelos próprios conselheiros, transforma-o em órgão pouco importante do ponto de vista prático, ainda que seja capaz de levantar discussões e analisar pontos que deveriam ser levados em conta na elaboração de uma política consistente para a radiodifusão e a imprensa.

Critérios políticos ou econômicos, tomados como valores absolutos, não são suficientes para garantir a pluralidade de fontes de informação. Para isso, é necessário aliar não só os critérios anteriormente mencionados, mas também políticas voltadas para uma maior democratização das comunicações, o que fica na dependência de uma ação decisiva por parte do Estado.

\section{Considerações finais}

Passados mais de 15 anos da promulgação da Constituição Federal, parte dos artigos constantes do título VIII, capítulo $\mathrm{V}$, referente à comunicação social, ainda não foi regulamentada. Por mais que se entenda a necessidade do estabelecimento, na Carta Magna, de idéias genéricas, é preciso reconhecer que não menos necessária é a consolidação de uma legislação que torne tais idéias exequíveis. A Lei Geral da Comunicação, defendida e in- 
centivada por diferentes atores ao longo da história da Nova República, voltou a ser debatida em 2005 como forma de regulamentação dos artigos 221 e 222 da Constituição Federal. Todavia, até a conclusão deste artigo, nada havia sido decidido.

O entendimento das Comunicações no Brasil e dos princípios que a regem de acordo com a Constituição Federal é prejudicado não somente pela inexistência de uma legislação complementar recente, mas também pela existência de um manancial legal ultrapassado, elaborado em sua quase integralidade durante o regime militar, dissociado de princípios democráticos e liberais propalados na Carta Magna de 1988. Causa estranheza a vigência, ao mesmo tempo, do capítulo referente à comunicação social na Carta Magna e da Lei de Imprensa, documento legal de 1967, fruto do regime de exceção. Atualmente, prevalece a interpretação parcial da Lei de Imprensa e de legislações semelhantes, de modo tal que não firam a Constituição Federal. Ainda assim, é uma situação esdrúxula, um arremedo jurídico que possibilita a coexistência de conjuntos legais de épocas díspares.

Dessa forma, peca-se no cumprimento da Constituição Federal, no que diz respeito às Comunicações, principalmente, pela inexistência de uma legislação complementar e em conformidade com a Carta Magna. Não foram criadas condições para que dela se faça uso pleno, prevalecendo a possibilidade de coexistência de múltiplas interpretações. Nesse sentido, o espaço de interpretação amplo favorece os que discordam dos princípios constitucionais, seja por concordarem com uma regulação mais autoritária para o setor - análoga às leis ainda vigentes desde o regime militar -, seja por não verem contempladas suas intenções empresariais nas idéias expostas pela Constituição Federal. Enquanto os princípios constitucionais não são integralmente regulamentados, prevalece a possibilidade de que não sejam cumpridos.

Assim, é impossível apontar o capítulo sobre Comunicação Social da Constituição Federal como o ponto de partida para a elaboração de políticas públicas consistentes para o setor. Por sua imprecisão e precária regulamentação, o texto constitucional serve, no máximo, como referência para o modelo de Comunicação Social defendido pelos parlamentares que fizeram parte da Assembléia Nacional Constituinte na década de 1980. Desse modelo podemos extrair idéias e princípios que motivem a elaboração e a adoção de políticas. No entanto, não se pode afirmar que no texto constitucional haja uma linha mestra que aponte alguma diretriz clara e prática para o setor. Mesmo assim, apesar dos problemas mencionados, não se pode negar que a Constituição Federal de 1988, ao contrário de suas antecessoras, promoveu um avanço significativo ao expor um esboço tênue de regulação para a Comunicação Social.

É importante ressaltar que o próprio Congresso Nacional é o grande obstáculo para a consolidação de políticas públicas para o setor e para a ampla regulamentação da matéria relativa à comunicação social. Entende-se a Constituição Federal, avanço democrático que é, como reflexo de idéias liberais (em sentido bem específico) comuns à época. Quando da sua promulgação, o país passava por um período de ruptura com as práticas autoritárias e de afirmação da liberdade em toda a vida pública, especialmente, no que se refere a setores que nas décadas anteriores foram, direta e indiretamente, afetados pela censura e pela coerção. Os parlamentares mostraram-se, então, cientes das mudanças no país, mas pecaram por não efetivarem os princípios constitucionais. É compreensível a falta de agilidade no Congresso Nacional no que toca à temática das Comunicações, quando observamos sua composição, já mencionada. É conveniente para eles que haja liberdade máxima e regulação mínima quanto à Comunicação Social no país, daí as dificuldades para a aprovação de medidas que não estejam de acordo com seus interesses.

A garantia dos princípios democráticos relacionados por Robert Dahl e discutidos neste artigo - liberdade de expressão e fontes de informação diversificadas - esbarra, pois, numa estrutura rígida, aglutinadora de interesses pessoais em grandes grupos marcados pela posse concentrada dos meios de comunicação. Imaginar uma lógica diversa da atual implica uma reordenação dos interesses concernentes aos atores ligados ao Estado - ou, de forma mais ampla, a esse próprio rol de atores e à sua natureza. 


\section{Referências}

ALTHUSSER, L. Aparelhos ideológicos de Estado: nota sobre os aparelhos ideológicos de Estado (AIE). 3.ed. Rio de Janeiro: Graal, 1987.

ARBEX JÚNIOR, J. Showrnalismo: a notícia como espetáculo. São Paulo: Casa Amarela, 2001.

BRASIL. Congresso Nacional. Concentração da mídia: debates no Conselho de Comunicação Social, 2004. Disponivel em: $<$ http://www2.senado.gov.br/ comissoes/ccs/docs.asp>. Acesso em: 23 jun. 2004.

Decreto no 1720, de 28 de novembro de 1995. Altera dispositivos do regulamento dos serviços de radiodifusão, aprovado pelo Decreto n- 52.795, de 31 de outubro de 1963, e modificado por disposições posteriores. Diário Oficial da República Federativa do Brasil,

Brasilia, DF, 29. nov. 1995 . Disponivel em: <http://wwwt.senado.gov.br/netacgi/nph-

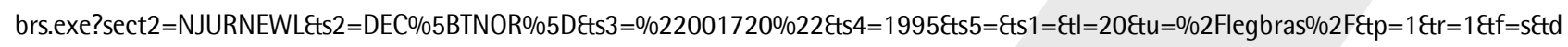
$=$ NJUR $>$. Acesso em: 2 jun. 2004.

. Lei no 10.610, de 20 de dezembro de 2002. Dispõe sobre a participação de capital estrangeiro nas empresas jornalísticas e de radiodifusão, sonora e de sons e imagens, conforme o parágrafo $4^{\circ}$ do artigo 222 da Constituição, altera os artigos 38 e 64 da Lei no 4.117 , de 27 de agosto de 1962, o parágrafo 3ㅇ do artigo 12 do Decreto-Lei oㅜ 236, de 28 de fevereiro de 1967, e dá outras providências. Diário Oficial da República Federativa do Brasil, Brasilia, DF, 23 dez. 2002. Disponível em: $<$ http://wwwt.senado.gov.br/netacgi/nphbrs.exe?sect2=NJURNEWLCts2=@docn\&ts3=\%22010610\%22\&ts4=2002\&ts5=\&ts1=\&t|=20\&tu=\%2Fl egbras\%2FEtp=1\&tr=1\&t=s\&t=NJUR>. Acesso em: 4 jun. 2004.

CAMPANHOLE, A.; CAMPANHOLE, H. L. Constituições do Brasil. São Paulo: Atlas, 1989.

COSTA, S.; BRENER, J. Coronelismo eletrônico: o governo Fernando Henrique e o novo capitulo de uma velha história. Comunicação \&t Política, Brasilia, v.4, n.2, p.29-53, 1997.

DAHL, R. La democracia y sus críticos. México: Paidós, 1991.

Sobre a democracia. Brasilia, DF: UnB, 2001.

HERMAN, E. S.; CHOMSKY, N. A manipulação do público: política e poder econômico no uso da mídia. São Paulo: Editora Futura, 2003.

MOTTER, P. 0 uso político das concessões das emissoras de rádio e televisão no governo Sarney. Comunicação \& Política, Brasilia, DF, v.1, n.1, p.89-116, 1994.

ROLDÃO, I. C. O governo FHC e a política de radiodifusão. In: CONGRESSO BRASILEIRO DE CIÊNCIAS DA COMUNICAÇÃO, XXII, 1999, Rio de Janeiro. Anais... Disponivel em: <http://www.intercom.org.br/papers/1999/gt27/27r03.pdf>. Acesso em: 2 jun. 2005.

SODRÉ, N. W. História da imprensa no Brasil. São Paulo: Mauad, 1999.

VIEIRA, R. A. Políticas nacionais de comunicação e capitalismo, dependente ou não. Comunicação \& Política, Rio de Janeiro, v.2, n.3/4, p.19-24, 1994. 